
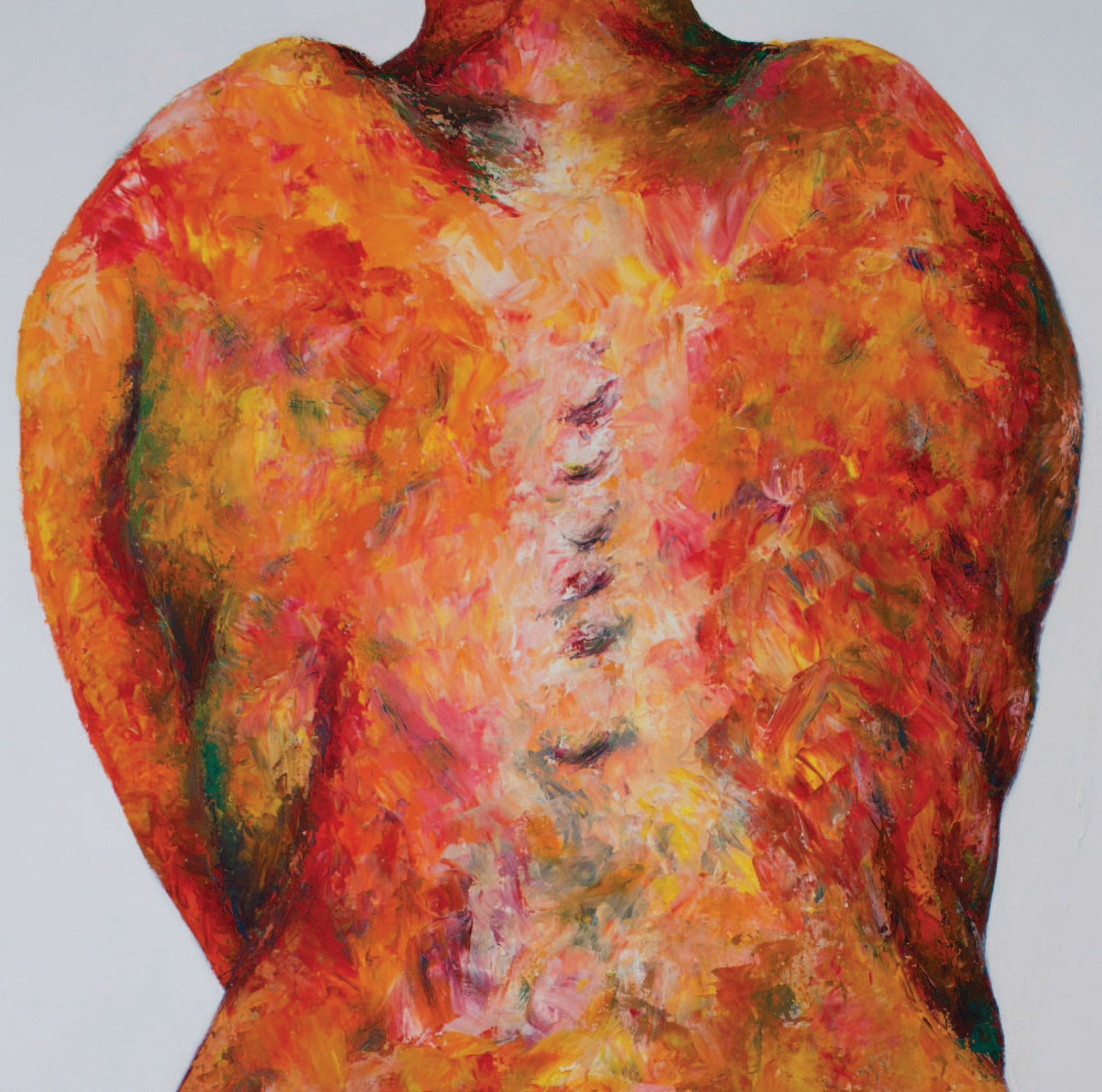

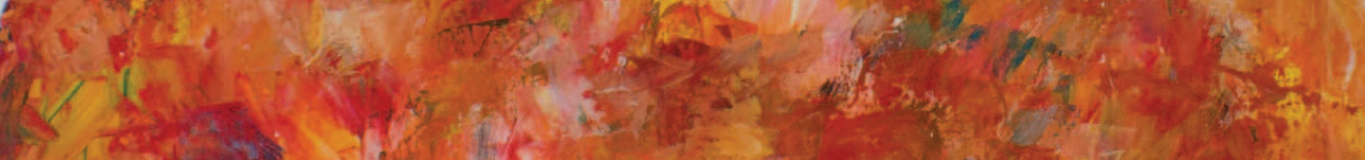

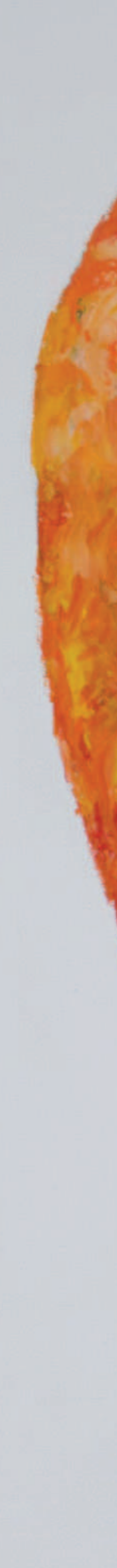

1

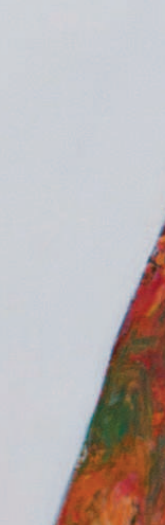

2.

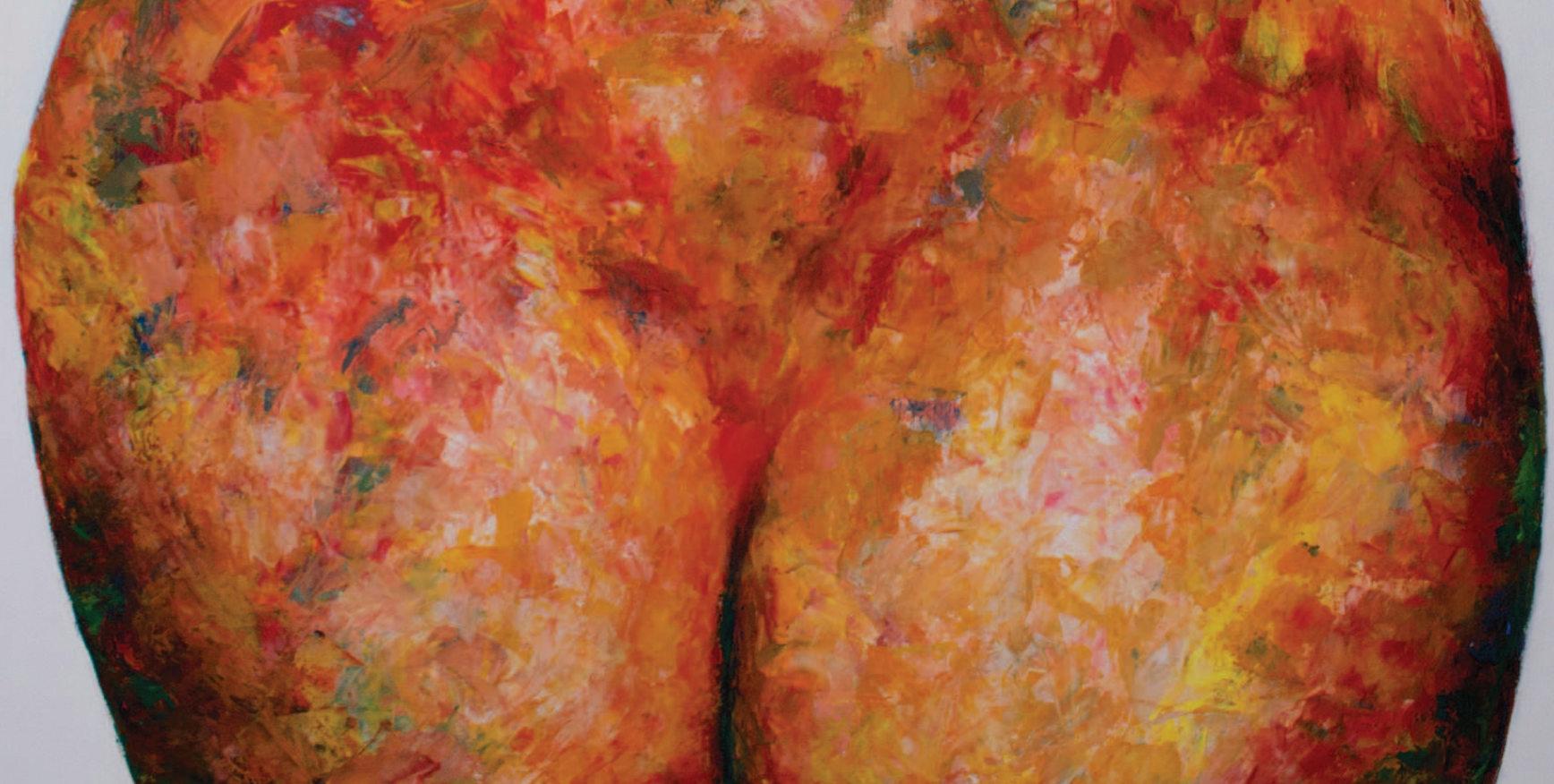




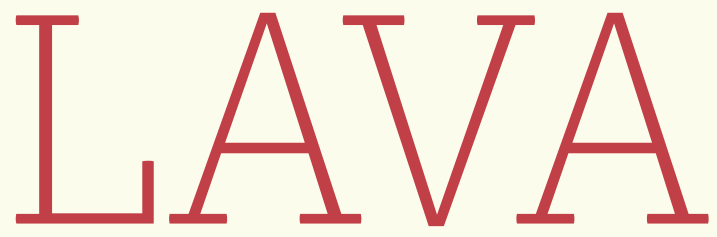

Matéria liquida lançada pelos vulcões.

Torrente, enxurrada, curso. 


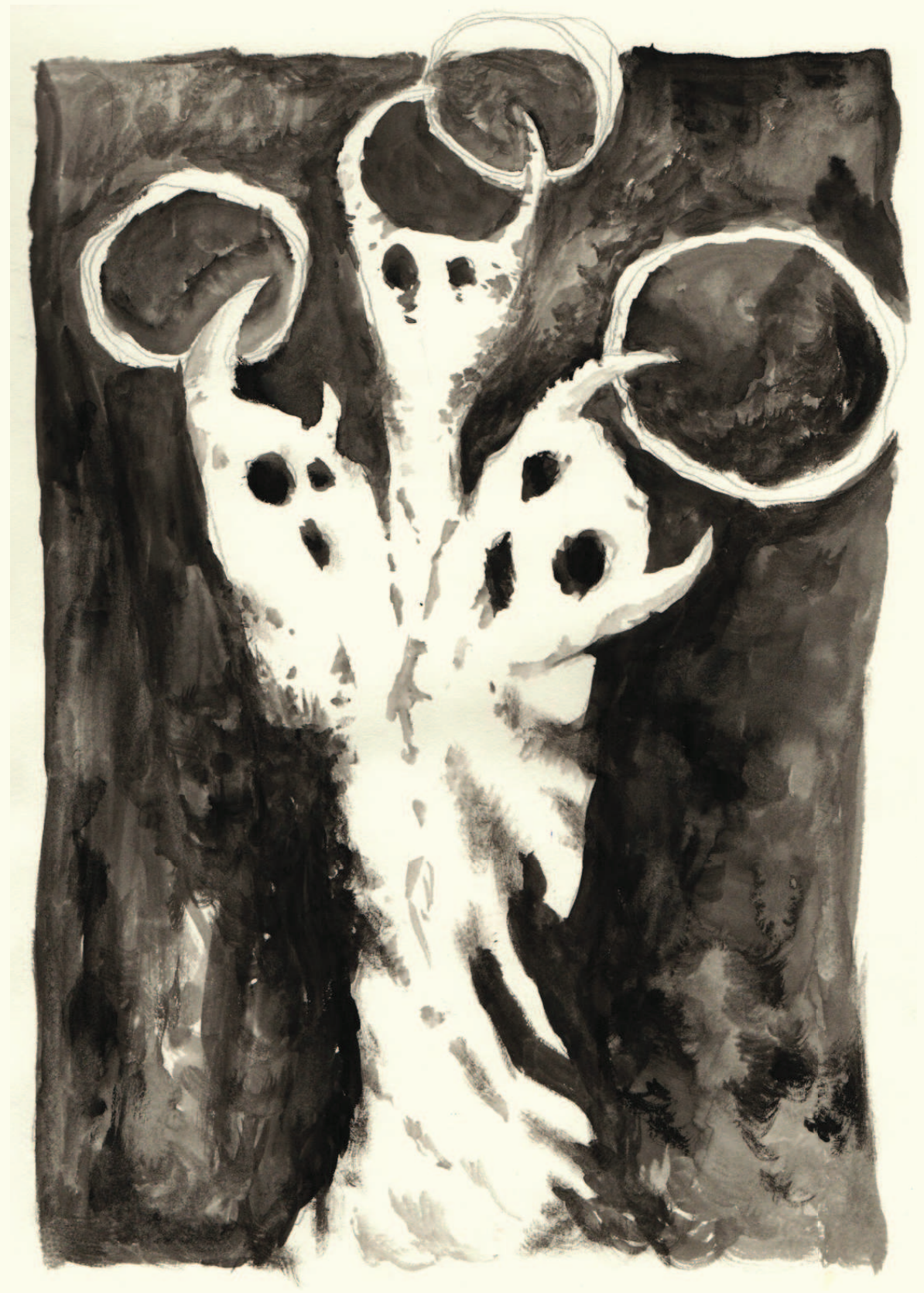

\section{ASPECTOS DA RELAÇÃO ENTRE EXPERIÊNCIA E NARRATIVA NA CONTEMPORANEIDADE}

Textos de conclusão do curso ministrado no segundo semestre de 2014 e indicados para publicação pela Profa Andrea Saad Hossne. 


\title{
LA DOULEUR \\ E A COMPREENSÃO DO CONTEMPORÂNEO
}

\author{
- LAURA DEGASPARE MONTE MASCARO
}

\section{RESUMO}

Neste trabalho, pretendemos analisar brevemente a obra La Douleur de Marguerite Duras principalmente em seu caráter de literatura de testemunho, enquanto uma literatura preocupada com o eu e com o mundo. Para a referida análise, partiremos de uma articulação entre o tratamento que Giorgio Agamben dá ao contemporâneo e aquele que Hannah Arendt dá ao pensar entre o passado e o futuro; em segundo lugarnos questionaremos acerca do tipo de compreensão trazida pela obra sobre o mundo a partir do "eu" que narra suas vivências, e finalmente consideraremos o modo pelo qual a obra alcançaria essa compreensão.

Palavras-chave: Literatura de Testemunho, Contemporâneo, Marguerite Duras, Hannah Arendt, Giorgio Agamben

\section{ABSTRACT}

This paper intends to analyze briefly Marguerite Duras' La Douleur specially concerning its character of testimonial literature, as a literature bound to the self and to the world. For this analysis, we will depart from an articulation between the treatment given by Giorgio Agamben to the contemporary and the one given by Hannah Arendt to the faculty of thinking between past and future; secondly, the work will raise a question about the kind of understanding brought by Duras' La Douleur on the world and the "self" that narrates its experiences, and finally we will consider the way by which the book reaches such understanding.

Keywords: Testimonial Literature, Contemporary, Marguerite Duras, Hannah Arendt, and Giorgio Agamben.

\section{INTRODUÇÃO}

巨 m sua obra La Douleur, de 1985, Marguerite Duras narra suas vivências enquanto membro da resistência à ocupação nazista na França, mais particularmente como integrante do Mouvement National des Prisonniers de Guerre et Déportés (MNPGD). Duras teve sua vida atravessada por esses eventos e a eles reagiu, não como quem a historiografia consideraria uma grande protagonista, mas como alguém 
que teve seu destino determinado pela política e pela história: seu marido, Robert Antelme ${ }^{1}$, foi preso e deportado para campos de concentração na Alemanha em virtude de sua atuação no movimento de resistência, o que acarretou uma suspensão no curso de sua existência.

O primeiro texto que compõe a obra e a ela confere seu título, é um récit aparentemente escrito concomitantemente às vivências de Duras na espera por seu marido deportado, e de sua chegada em deploráveis condições físicas e psicológicas. Teria por fonte os diários pessoais da autora escritos em 1945. Os outros textos que compõe La Douleur também trazem relatos do período: do movimento de resistência, da liberação, da Justice de l'épuration ${ }^{2}$ ao fim da segunda Guerra Mundial, sejam eles expressamente testemunhais ou ficcionais ${ }^{3}$.

Os textos testemunhais oferecem a reconstituição de uma arqueologia pessoal da dor, do ponto de vista da autora-narradora-personagem em primeira pessoa, ou de alguém que figura em seu lugar em terceira pessoa. Estaríamos, assim, principalmente diante do que se denomina literatura de testemunho, embora muitas vezes essa literatura de testemunho contenha traços autobiográficos e daquilo que se denomina autoficção ${ }^{4}$.

O testemunho, e com ele a literatura de testemunho que surge após a Segunda Guerra Mundial, tem uma relevância que nos obriga a rever todas as noções herdadas de séculos de filosofia, historiografia, de teoria literária e dos gêneros. A literatura de testemunho seria mais do que um gênero, sendo uma face da literatura que vem à tona na época de catástrofes - cada vez mais presentes e constantes, como

[1] Robert Antelme escreveu o livro L'Espèce humaine (1947) para dar conta de suas vivências como deportado nos campos de concentração, trazendo não apenas um relato testemunhal escrito a posteriori, mas um livro dos campos, que podemos crer ter sido começado nos campos, como forma "silenciosa" de luta contra aqueles que tentavam Ihe negar a humanidade e como tentativa de superar "la distance que nous [os deportados] découvrions entre le langage dont nous disposions et cette expérience que, pour la plupart, nous étions en train de poursuivre dans notre corps." (ANTELME, 1957, p. 9). Seu livro é uma referência naquilo que chamamos da literatura de testemunho após Auschwitz.

[2] Trata-se de um movimento ocorrido após a Libertação da França do domínio alemão de "justiça de purificação", no qual colaboradores - e mesmo pessoas ligadas aos colaboradores - foram perseguidos e punidos de forma violenta com execuções sumárias, processos iníquos, linchamentos e humilhação de mulheres que tiveram relações amorosas com nazistas ou colaboracionistas.

[3] Os dois últimos textos, apesar de essencialmente vinculados por sua temática à Segunda Guerra Mundial, são expressamente ficcionais, e não teriam a mesma pretensão "testemunhal” que os demais. Nas palavras de Duras (1985, p. 194): "C'est inventé. C'est de la littérature".

[4] Veremos que muitas vezes essa literatura de testemunho tem traços de autoficção, principalmente quando narrada no presente, apesar de não poder ser caracterizada dessa forma segundo a perspectiva francesa, principalmente por não ter a forma de um romance. 
diagnosticara Walter Benjamin - e que compele à revisão de toda a história da literatura a partir do questionamento de sua relação e compromisso com o real ${ }^{5}$.

A literatura de testemunho se articula entre a necessidade premente de narrar a experiência vivida, e a percepção da insuficiência da linguagem diante dos fatos (SELigmann-SilVA, 2003, p. 46). Acrescentamos $^{6}$ a essa articulação a questão da impossibilidade de uma memória plena e total dos eventos vividos, a passagem do tempo e a transformação do sujeito autor ${ }^{7}$. O próprio Robert Antelme, no início de seu relato L'Espèce Humaine conta a distância entre a experiência vivida nos campos de concentração e a linguagem de que dispunha. Outra dificuldade nesse relato é a dificuldade do distanciamento dessa experiência. Ele relata: "nós ainda estávamos lá", o que nos permite inferir não que ele ainda estava no campo, mas que o campo ainda estava nele, o havia transformado.

Vale destacar que diferentemente do gênero autobiográfico ou do que se classifica mais recentemente como autoficção, a literatura de testemunho não é centrada apenas na constituição do "eu" ou na sua reinvenção, mas também têm uma preocupação com o elemento "real" "que perpassa a experiência vivida, e assim vincula-se também aos acontecimentos que foram compartilhados com o mundo ${ }^{9}$, e à história humana. Arriscamos argumentar que o testemunho, nesse caso, constitui-se com base em uma dupla perspectiva, que pode ser explicada com base na noção linguística

[5] Aqui, o real não deve ser confundido com a "realidade" tal como pensada pelo romance naturalista e realista, mas como um evento vivido, inscrito na mente e corpo daqueles que o experienciaram tanto quanto na História do mundo, e que resiste à representação tal como um trauma.

[6] No campo da teoria literária acerca da autobiografia, o questionamento da unidade do sujeito já vinha sendo realizado pelo menos desde Paul de Man, em seu artigo "Autobiography as De-facement" de 1979, onde ele a partir de uma filosofia desconstrucionista, não apenas coloca em questão a pretensão de verdade mimética da representação autobiográfica, afirmando que "It appears, then, that the distinction between fiction and autobiography is not an either/or polarity but that it is undecidable." (DE MAN, 1979, p. 921), como também evidencia a ilusão de uma vida e de um sujeito unificado no tempo que servem de referência à obra, colocando em xeque a própria existência do sujeito. Ao que nos parece, a crítica da representação do real já havia sido discutida em relação ao conceito de literatura de testemunho, no entanto, a crítica à unidade do sujeito, como aquela operada por Beatriz Sarlo parece ser mais recente.

[7] Que na maioria das vezes se identifica com o narrador e personagem em primeira pessoa.

[8] Quase sempre traumático (SELIGMANN-SILVA, 2003, p. 48)

[9] Que seria esse espaço entre os homens, que se forma quando nos agrupamos, conforme a teoria de Hannah Arendt. 
trazida por Barthes, a diátese ${ }^{10}$; sendo que aquele que testemunha ocupa a posição ativa, como se testemunhasse algo que está fora dele (o real, o acontecimento), e média, em que testemunha a sua própria vivência.

Nesse sentido, também possui uma vinculação com o presente, com o que é contemporâneo. Mesmo quando se coloca como ato de memória, busca resgatar o que foi vivido como presente, e assim tem o compromisso de narrar e conferir um sentido ao contemporâneo, à sua própria época.

Assim, pretendemos realizar uma breve análise da obra La Douleur de Marguerite Duras principalmente enquanto literatura de testemunho, partindo, primeiramente, de uma articulação entre o tratamento que Agamben dá ao contemporâneo e aquele que Arendt dá ao pensar entre o passado e o futuro; em segundo lugar, do questionamento acerca do tipo de compreensão trazida pela obra sobre o mundo a partir do "eu" que narra suas vivências, e finalmente do modo pelo qual a obra alcançaria essa compreensão.

\section{MARGUERITE DURAS ENTRE O PASSADO E O FUTURO}

Como dissemos, o período de dominação da França pela Alemanha durante a Segunda Guerra mundial provocou uma espécie de suspensão no curso da vida de Duras. Suspensão esta que coincide, no plano histórico, ao "intervalo de tempo totalmente determinado por coisas que não são mais e por coisas que não são ainda" (ARENDT, 2003, p. 35-6). No entanto, tanto no plano da compreensão do eu, da identidade, como no plano da compreensão do mundo, esses hiatos na existência, assim como na história, podem conter o momento da verdade ${ }^{11}$.

Arendt, no prefácio de Entre o passado e o futuro trata da experiência do poeta René Char na resistência francesa - experiência esta compartilhada por Duras. O colapso da França esvaziara o cenário político do

[10] A "diátese" designa a forma como o sujeito do verbo é afetado pelo processo. Ele utiliza o verbo sacrificar (ritualmente) como exemplo, em que "é ativo se é o sacerdote que sacrifica a vítima em meu lugar e por mim, e é médio se, tomando, de certo modo, o cutelo das mãos do sacerdote, eu mesmo faço o sacrifício por minha própria conta; no caso ativo, o processo realiza-se fora do sujeito, pois, se é verdade que o sacerdote faz o sacrifício, não é afetado por ele; no caso médio, ao contrário, ao agir o sujeito afeta-se a si mesmo, permanece sempre no interior do processo, mesmo que esse processo comporte um objeto.” (BARTHES, 2004, p. 22)

[11] A verdade aqui não pode ser entendida em sua acepção moderna e inequívoca, como algo que se deduz do processo da história, tendo em vista que a própria Arendt (2003, p. 41), em outro momento, ressalta que os exercícios do pensamento e da compreensão põem em suspenso o "problema da verdade". 
país e os poetas e intelectuais da época viram-se sugados para a política (ARENDT, 2003, p. 29). Após alguns anos, foram liberados deste "ônus" e retornaram a seus afazeres, sendo mais uma vez, como Char coloca, "separados do 'mundo da realidade' por uma épaisseur triste de uma vida particular centrada apenas em si mesma". Arendt pretende definir melhor o que seria o "tesouro" que teve de ser abandonado por esses intelectuais quando os "anos essenciais" terminaram, e chega à seguinte formulação:

[...] parece ter consistido como que de duas partes interconectadas: tinham descoberto que aquele que "aderira à Resistência, encontrara a si mesmo", [...] podendo permitir-se "desnudar-se". [...] assim, sem sabê-lo ou mesmo percebê-lo, [haviam] começado a criar entre si um espaço público onde a liberdade poderia aparecer. (ARENDT, 2003, p. 29)

Por um lado, aqui, é possível perceber como a experiência da política pode ser transformadora e reveladora, ao mesmo tempo do mundo e do indivíduo. Nesse sentido, a dimensão subjetiva está intimamente conectada à vida pública ${ }^{12}$. Por outro lado, é preciso saber como lidar com o legado de transformações do que foi vivenciado durante a Segunda Guerra Mundial, para superar o hiato provocado também pelo evento da Shoah - que não poderia ser dissociado da experiência da Resistência -, de uma violência e irracionalidade sem precedentes, que provocou uma ruptura entre o passado e o futuro. Seja na vida dos membros da resistência, seja na tradição europeia herdada do passado, esses anos representaram uma ruptura, que refletiu em um hiato compreensivo no plano pessoal e coletivo - "notre héritage n'est précédé d'aucun testament" (CHAR, 1946, apud ARENDT, 2003, p. 28).

Segundo Arendt (2003, p. 31), o tesouro dos membros da resistência foi perdido e essa perda "consumou-se, de qualquer modo, pelo olvido, por um lapso de memória que acometeu não apenas os herdeiros, como, de certa forma, os atores, as testemunhas, aqueles que por um fugaz momento retiveram o tesouro nas palmas de suas mãos; em suma, os próprios vivos." Para evitá-la e saber como rearticular o passado e projetar o futuro, era preciso que ao ato, ao acontecido, fosse dado um acabamento pensado após o ato. 
Vale destacar que Arendt vincula a atividade do pensar com o lembrar, afirmando ser a memória um dos mais importantes modos do pensamento. As lembranças constituem os fios que serão tecidos e articulados pelo pensamento. Mas como dar esse acabamento àquilo que foi vivido contemporaneamente?

Conforme o pensamento de Giorgio Agamben (2009, pp. 58-59), o contemporâneo é aquele que pertence verdadeiramente ao seu tempo, mas que não coincide perfeitamente com ele, sendo exatamente por isso, por conta desse deslocamento, capaz de percebê-lo e apreendê-lo. Assim, a relação do homem contemporâneo com seu próprio tempo é de uma aderência por meio de uma dissociação e de um anacronismo. Consideramos adequada a aproximação dessa noção do contemporâneo à parábola de Kafka da qual se utiliza Hannah Arendt para explicitar o que significa estar "entre o passado e o futuro".

A autora busca encontrar o lugar do pensamento entre as forças antagônicas do passado e do futuro que comprimem o homem que luta contra elas $^{13}$. Na referida parábola, a única solução desse impasse seria que o homem que vive no intervalo entre o passado e o futuro saltasse para fora da linha de combate e fosse alçado à posição de juiz sobre os adversários que lutam entre si. Arendt (2003, pp. 37-38) observa que à parábola kafkiana deste evento-pensamento falta uma dimensão espacial em que o pensar possa ser exercido sem ser forçado a saltar para fora do tempo humano. Nesse sentido, o pensar sobre os eventos vividos e sobre o presente não poderia ser exercido de fora do tempo humano: é preciso que haja uma aderência a essa posição presente ${ }^{14}$ - com o que concorda Agamben. Arendt (2003, p. 41) afirma: "[...] meu pressuposto é que o próprio pensamento emerge de incidentes da experiência viva e a eles deve permanecer ligado, já que são os únicos marcos por onde pode obter orientação."

A partir daí, podemos caracterizar a obra La Douleur como fruto da postura contemporânea de Duras. Em primeiro lugar, é preciso pensar que embora a maior parte dos textos da obra tenham sido escritos a posteriori, sejam eles expressamente testemunhais ou ficcionais, eles são narrados

[13] É interessante notar que não apenas o passado espreita e comprime o presente, mas também o futuro, que remete a mente do homem de volta ao passado. Nesse evento-pensamento, o tempo não é um contínuo, mas é partido ao meio, cindido apenas pela inserção do homem nessa temporalidade.

[14] Na denúncia de Nietszche contra posições da história traduzidas em poder simbólico, ele trata de uma direção sobre o pensamento, que seria repressora dos impulsos do presente (SARLO, 2005, p. 10-11). Na visão de Arendt a partir de Kafka, pelo contrário, as forças vêm de duas direções e o deslocamento do pensamento ainda lastreado no presente é que permitiria ao homem ser juiz dessa batalha. 
em grande parte no presente, sendo que o primeiro possui notas temporais, datações mais ou menos precisas introduzindo cada parte, tendo em vista tratar-se de um diário recuperado. Desse modo, existe um compromisso da autora, o que é um traço característico de sua obra em geral, em narrar no presente, inserindo-se naquilo que é vivido contemporaneamente, mesmo que o empreendimento narrativo que articula a memória seja posterior.

Por outro lado, embora Duras se insira como narradora e muitas vezes personagem nesse presente, ela também consegue operar um deslocamento necessário para sua compreensão. Isso também a caracteriza como uma autora comprometida com a compreensão de si própria e do mundo. Não podemos esquecer que a publicação de La Douleur, seguiu justamente o conselho de Arendt (2003, p. 35-6) aos historiadores e àqueles comprometidos em pensar o hiato entre o passado e o futuro: sua mente foi obrigada a dar duas reviravoltas: primeiro ao escapar do pensamento para a ação, e a seguir, quando a ação, ou antes, o ter agido, forçou-a de volta ao pensamento.

Isso fica mais evidente nos textos "Albert des Capitales" e "Ter le milicien" em que ela separa e distancia do diário "La douleur" "pour que cesse le bruit de la guerre, son fracas" (DURAS, 1985, p. 138), estabelecendo assim um distanciamento. Contudo, esse distanciamento pode ser interpretado de diversas maneiras: o "écart" existe a princípio ${ }^{15}$ tanto entre os momentos de elaboração dos textos, como também é uma separação física, em seções diferentes, com preâmbulos próprios que fornecem chaves de interpretação diversas, sendo que "La douleur" poderia ser visto como um rastro, um instrumento de hypómnesis, um registro do que foi vivido como presente no presente, e os textos mencionados - "Albert des Capitales" e "Ter le milicien" - como um registro da memória de uma experiência passada, sobre a qual incide não apenas a impossibilidade da totalidade da percepção do mundo, como também o esquecimento, o trauma. No entanto, acreditamos que mesmo no caso do diário "La douleur", as reviravoltas entre a ação e o esforço compreensivo estejam presentes em alguma medida, e isso se dá por meio de uma releitura e reescritura desse diário.

Assim, muito embora o tempo narrativo dos textos seja o do presente da guerra, tendo sido os diários que deram origem a "La douleur" redigidos aparentemente em 1945 ou pouco tempo depois, a publicação do livro deu-se em 1985, sendo que uma versão desse texto foi publicada 
anteriormente em 1976 na Revue Sorcières. Em um preâmbulo ao primeiro texto intitulado "La douleur", a autora, que então se coloca fora da narrativa, estabelecendo o vínculo desta com o vivido, escreve:

J'ai retrouvé ce Journal dans deux cahiers des armoires bleues de Neauphle-le-Château.

Je n'ai aucun souvenir de l'avoir écrit.

Je sais que je l'ai fait, que c'est moi qui l'ai écrit, je reconnais mon écriture et le détail de ce que je raconte, je revois l'endroit, la Gare d'Orsay, les trajets, mais je ne me vois pas écrivant ce Journal (...)

Ce qui est sûr, évident, c'est que ce texte-là il ne me semble pas pensable de l'avoir écrit pendant l'attente de Robert $L$.

\section{(...) La première fois que je m'en soucie, c'est à partir d'une demande que me fait la revue Sorcières d'un texte de jeunesse.}

(DURAS, 1985, p. 12)

Embora não tenhamos tido contato com os manuscritos, sequer com a edição de 1976, supomos que tenha havido um trabalho de reescritura desse texto après-coup, quando ela se volta para o passado e para seus manuscritos não se lembrando sequer de ter narrado essas vivências.

Esse preâmbulo suscita diversas questões que não podem ser respondidas, mas que nos apontam para a forma como se dá essa narrativa do contemporâneo e com ela a articulação do pensamento. Seria o registro encontrado nos cahiers coerente com a memória viva da autora em relação ao ocorrido? Provavelmente não, pois eles se distinguem essencialmente enquanto presença e ausência. Seria a memória viva de Marguerite mais verdadeira do que o rastro ${ }^{16}$ ? Talvez mais condizente com essa própria mnéme (memória), no entanto, talvez não tão condizente com a mulher que viveu os fatos narrados. Talvez essa mulher

[16] O rastro (trace) é um conceito extraído da obra de Jacques Derrida que se vincula geralmente ao retorno ao vivido. É o fundo sobre o qual se inscrevem a escritura, o rastro, o arquivo etc. Em geral relaciona-se à ausência, como no caso da escritura, ou às inscrições da presença, como no caso da memória ou do trauma. Neste caso, o "rastro" refere-se ao registro do vivido pela escritura, em oposição à memória viva. Basta que algo seja inscrito para que seu rastro permaneça, correndo sempre o risco de ser apagado mais tarde. A realidade de algo é seu próprio rastro. Não houve jamais a coisa em si, porque aquilo que ocupava o lugar da origem era desde sempre um rastro. 
tenha mudado, sofrido uma transformação e, com ela, essa memória viva. No entanto, esse rastro, instrumento de hypómnesis (rememoração) permaneceu estático no tempo.

E no momento da leitura, pela autora, de seu relato, ocorre o encontro entre as duas Marguerites, o encontro da escritora com um espectro. Diante disso, ela questiona a adequação da palavra "écrit" para a atividade que realizou e para o produto de tal atividade, uma vez que a palavra, do modo como foi usada, designa tanto a atividade da écriture, de abertura desse caminho, quanto o rastro em si: "La Douleur est une des choses les plus importantes de ma vie. Le mot 'écrit' ne conviendrait pas. Je me suis trouvée devant un désordre phénoménal de la pensée et du sentiment auquel je n'ai pas osé toucher et au regard de quoi la littérature m'a fait honte." (DURAS, 1985, p. 12)

Além disso, quando pensamos na realidade vivida enquanto trauma, não podemos deixar de lembrar como a psicanálise vê esse "armazenamento" do passado: enquanto inscrição, que é sempre lida après-coup (SEligmanN-SILVA, 2003), o que coincide com a forma como esse "écrit" foi lido pela autora. Aliás, a própria forma como o diário foi escrito e redescoberto imitam a forma de inscrição e (não)memória do trauma, a estrutura do trauma, visto que o diário contém a inscrição de vivências da autora em uma camada profunda, nos "cahiers des armoires bleues de Neauphle-le-Château", da qual ela não tem nenhuma lembrança, mas que no entanto marca profundamente sua vida e a identidade, como a coisa mais importante de sua vida, e a qual emerge involuntariamente quando menos se poderia esperar, como memória involuntária.

Desse modo, o pensar o contemporâneo é derivado essencialmente da experiência vivida no presente, ao mesmo tempo em que promove um deslocamento, encontra um espaço ainda no tempo humano para olhar para as forças do passado e do presente que o comprimem. A partir de uma "guinada subjetiva" ocorrida no século XX e analisada por Beatriz Sarlo, na inscrição da experiência passou a se reconhecer uma verdade, uma fidelidade ao ocorrido. Contudo, na visão da autora, não é o bastante supor que a hipotética continuação entre experiência e relato garanta uma representação verdadeira ou uma maior compreensão do ocorrido. É preciso que na representação da memória da experiência incida o pensamento e o julgamento. Como coloca Sarlo (2005, p. 26), citando Susan Sontag, "Talvez se dê valor demais à memória e um valor insuficiente ao pensamento".

Por um lado, quando tratamos da representação da memória, mesmo que de um passado recente, é preciso que se reconheça que a origem dessa representação é múltipla. Distanciamo-nos com base 
em um pensamento desconstrutivo ${ }^{17}$ do conceito platônico de mimese, comandado pela hierarquia entre o imitante e o imitado, com base em uma lógica da identidade que remete sempre a uma origem simples. No caso dos textos de pretensão testemunhal em La Douleur, a origem é claramente múltipla: os fatos vivenciados pela autora no movimento de resistência francesa e de justice d'épuration; a memória viva da autora no momento da narração do ocorrido; o reordenamento (ou desordenamento), e a recriação dessa memória para que pudesse ser convertida em uma narrativa.

Por outro lado, é importante destacar que tanto a experiência como a atividade da lembrança só contribuem para a compreensão do ocorrido na medida em que integram a atividade do pensar, que consiste, no caso de uma narrativa, no processo de reordenamento e recriação a partir da lembrança. Apenas no pensamento pode o homem habitar a lacuna ${ }^{18}$ entre o passado e o futuro, sendo que no plano absolutamente concreto, a seta do tempo continua a correr exclusivamente para frente e o presente, como vimos, é deixado para trás, só podendo ser recuperado precariamente na atividade da rememoração, ou por meio dos rastros.

Selligmann-Silva (2003, p. 50) compartilha essa visão, concordando com o fato de que muito se produziu no sentido de aumentar nosso conhecimento acerca dos eventos - da Shoah - em si, mas que nossa compreensão desses eventos continua sendo um trabalho em andamento e sempre incompleto, porquanto lida com o próprio pensamento e suas categorias. Nesse sentido, nos questionamos: a obra La Douleur teria procurado alcançar essa compreensão? Como? Para responder a essas questões, primeiramente traçaremos um caminho para esclarecer os pressupostos teóricos dos quais partimos para a análise da obra.

[17] Derrida trata de duas formas de pensar a origem: a primeira, comandada pela lógica da identidade (ilusão transcendental), em função da presença em todas as suas formas; a segunda que não remete a um centro transcendental, mas a uma origem sempre dividida, a uma dupla fonte (NASCIMENTO, 2001, p. 70-71). Em consequência, ao operar uma crítica da metafísica da presença, Derrida nos permite analisar o jogo representativo do ponto de vista da desconstrução, do fato que esse jogo está presente na dinâmica da memória e de sua representação.

[18] Para Arendt (2003, p. 40): "[a lacuna] bem pode ser a região do espírito, ou antes, a trilha plainada pelo pensar, essa pequena picada de não-tempo aberta pela atividade do pensamento através do espaço-tempo de homens mortais e na qual o curso do pensamento, da recordação e da antecipação salvam o que quer que toquem da ruína do tempo histórico e biográfico." Curioso notar que Derrida comparava metaforicamente a escrita e a inscrição com a abertura de uma trilha, de um caminho, com uma "picada", citando Lévi-Strauss. 


\section{COMPREENSÃO A PARTIR DAS FACULDADES DE PENSAR E JULGAR}

Em primeiro lugar, é preciso destacar que utilizamos a palavra "compreensão" em vez de "entendimento" ou "conhecimento", porque estes últimos estariam vinculadas ao que Kant chama de intelecto (Verstand), ao passo que a compreensão ao que ele denomina razão (Vernunft). Em sentido amplo, este último visa à elaboração de um sentido, enquanto que o primeiro a uma cognição, à apreensão por meio de percepções que são dadas pelos sentidos, objetivando um conhecimento verificável (ASSY, 1997), o que é justamente o que o testemunho não pode fornecer, embora muitas vezes tenha essa pretensão ${ }^{19}$.

Sarlo (2005) sugere que é justamente desse imediatismo da percepção e daquilo que é familiar que o testemunhodeve se afastar para que se constitua a partir do pensar. Assim,o pensamento diz respeito ao desvelamento do sentido, à necessidade de compreensão, e não à busca pela verdadeenquanto adequação da metafísica clássica.

Como foi posto anteriormente, a literatura de testemunho teria uma forte vinculação com a atividade compreensiva, sendo que a busca de sentido nos acontecimentos do mundo permite evitar a reedição, no caso da Segunda Guerra, de mecanismos de exclusão, violência e aniquilamento. Nesse sentido, a faculdade de julgar ${ }^{20}$, que é uma forma de construir uma ponte entre o eu e o mundo, deve ser considerada como fonte dessa compreensão. Embora a faculdade de julgar seja distinta do pensar, ela está ligada à corrente livre do pensamento, da qual se alimenta: "como uma faculdade distinta do pensar e do querer, no pluralismo do cogito arendtiano é a capacidade de lidar com o particular sem perder o horizonte do seu significado geral." (LAFER, 2007, p. 299).

Essa compreensão se daria com base no senso comum que, por seu turno, depende da capacidade de imaginação e de representação, de sair em visita ao outro, ou seja de um deslocamento. Gadamer, em Verdade e

[19] Segundo Sarlo (2005, p. 48), "Todo testemunho quer ser acreditado e, no entanto, não carrega consigo as provas pelas quais pode comprovar sua veracidade." Ainda, "O testemunho, por sua auto representação como verdade de um sujeito que relata sua experiência, pede para não ser submetido a regras que se aplicam a outros discursos de intenção referencial, alegando a verdade da experiência [...]”.

[20] Vale destacar que Arendt dedicou-se a pensar a faculdade de julgar no fim de sua vida, pois procurava um juízo de tipo reflexivo e não determinante, uma vez que em uma época de ruptura ou de inversão completa dos valores que conhecíamos como certos, não é possível "subsumir o específico a 'universais' normativos esgarçados e fugidios" (LAFER, 2007, p. 299). Para constituir essa faculdade, ela trouxe para o campo ético o modo do julgamento estético kantiano. No entanto, ela faleceu quando ia começar a redação de "o julgar" que complementaria "o pensar" e "o querer" da obra A vida do espírito. 
Método, traz a ideia de sensus communis, que serviria de base para uma verdade não científica - baseado no ideal da eloquência e em vez do método. O que é importante destacar aqui é que o sensus communis não se alimenta do verdadeiro como mimético, mas do verossímil: trata-se de um saber baseado não em razões, mas que permite encontrar o que é plausível, o que poderia acontecer. Segundo Leyla-Perrone Moisés (2006, p. 108), na representação do que poderia ter acontecido, revela-se as possibilidades não realizadas do real.

O sensus communis seria muito mais uma virtude social, sem a qual o homem não estaria preparado para interação civilizada, pressupõe um mundo compartilhado e que possuímos um senso que ajusta os dados sensoriais estritamente particulares aos dos outros, ao passo que a lógica independe da existência de outras pessoas (ARENDT, 2003, p. 339-40). Essa forma de pensar possibilitaria o cumprimento da tarefa ética de ajustamento a situações sempre novas exigida pela vida, evitando erros dogmáticos, assim como seria indispensável na modalidade retrospectiva do espectador e para lastrear a compreensão do historiador. Para tanto, seria preciso, segundo Gadamer, descobrir nas palavras a corrente livre do pensamento, ou, como colocaria Arendt, pensar com a "mentalidade alargada"21, o que significa treinar a imaginação para sair em visita, alheando-se do mundo e até da identidade que se tornou demasiadamente familiar, e depois retornando a nós mesmos:

Para conhecer ${ }^{22}$, a imaginação precisa desse passeio que a leva para fora de si mesma, e da volta reflexiva; em sua viagem aprende que a história nunca poderá ser contada totalmente e se encerrará, porque todas as posições não podem ser tomadas e tampouco sua acumulação resulta em uma totalidade. (SARLO, 2005, p. 53-4) (grifos nossos)

Acreditamos que a obra La Douleur foi escrita a partir desse esforço compreensivo, seja em seus textos considerados testemunhais, seja naqueles ficcionais. A solidão da escritura era para Duras um modo de se conectar com o mundo e de pensar: "Il y a ça dans le livre: la solitude

[21] "To exercise this kind of imagination is the condition for judgement. The enlargement of mentality permits you to take account the perspective of others as well as their circumstances. It means to judge from a perspective which is not your own. The world presents itself always to an enormous number of such perspectives; it is common to all of us precisely because each one of us sees it in a different perspective." (ARENDT, contêiner n. 58 - 023609, apud, LAFER, 2007, p. 300)

[22] Já destacamos que consideramos inadequado o uso da palavra "conhecer", sendo que "compreender" seria a palavra mais adequada. 
y est celle du monde entier. Elle est partout. Elle a tout envahi. [...] [La solitude] sans quoi on ne regarde plus rien. C'est une façon de penser, de raisoner [...]". (DURAS, 1993, p. 38)

\section{LA DOULEUR}

A centralidade da memória e do testemunho a partir da Segunda Guerra Mundial, seja para a história, seja para a literatura, traduz-se hoje como uma tendência acadêmica e do mercado de bens simbólicos que se propõe a reconstituir a tessitura da vida e a verdade com base na rememoração da experiência e na revalorização da primeira pessoa como ponto de vista, ou seja, da reivindicação de uma dimensão subjetiva (SARLO, 2005, p. 21). Como vimos, a literatura contemporânea deparou-se, após o advento da Shoah, com a necessidade de lembrança e expressão, e a simultânea intraduzibilidade dos acontecimentos, o que levou o trabalho da memória para o seu epicentro, sendo a literatura de testemunho a literatura par excellence da memória. No entanto, acreditamos que para que a literatura de testemunho possa de fato comprometer-se com uma compreensão tanto do $e u$, como do real, é preciso que a dimensão meramente subjetiva seja extrapolada, para que não se perca de vista o horizonte do significado geral dos acontecimentos. O próprio Walter Benjamin (1989, p. 107) afirma que só há experiência em sentido estrito, "quando entram em conjunção, na memória, certos conteúdos do passado individual com outros do passado coletivo".

Nesse sentido, vejamos como a obra La Douleur consegue ultrapassar essa dimensão. Embora a obra tenha lastros claros nas vivências da autora ao longo da guerra, ela vai além da pretensão de narrar os fatos tal como ocorreram ou tal como ela os vivenciou, operando um deslocamento e uma ampliação do eu, colocando em xeque o próprio sujeito que afirma-se como sujeito enquanto não só vivencia as experiências, como também pode comunicá-las e dá-las a conhecer plenamente. Duras (1993, p. 98) escreve "à cause de cette chance que j'ai de me mêler de tout, à tout, cette chance d'être dans le champ de la guerre, dans l'élargissement de cette réflexion [...]" $\mathrm{O}$ ato de escrever para ela é o próprio exercício da mentalidade alargada.

Em primeiro lugar, o "écart" que mencionáramos entre os textos expressamente testemunhais - o primeiro texto intitulado "La douleur", que neste aspecto que discutiremos aproxima-se do texto "Monsieur X. Dit Ici Pierre Rabier", e os textos "Albert des Capitales" e "Ter le milicien" - também fica evidente na mudança do foco narrativo, sendo que 
os primeiros textos estão em primeira pessoa e os últimos em terceira. Duras coloca em seu lugar uma personagem chamada Thérèse, mas deixa claro no preâmbulo: "Thérèse c'est moi. Celle qui torture le donneur, c'est moi. De même celle qui a envie de faire l'amour avec Ter le milicien, moi." Mas porque a existência desse personagem?

Essa é uma das formas em que Duras exercita o "sair em visita" em sua poética ${ }^{23}$. Ela promove aqui uma "mentira", um alheamento de si, mesmo que ao fim desse movimento ela volte a se debruçar sobre si própria. Thérèse constitui uma das possibilidades de existência da autora/ narradora e nesse sentido esses textos se aproximam da autoficção. Ela opera aqui o que Philippe Vilan chama de "mouvement de décentrement/ recentrement", que difere daquele mais propriamente egocêntrico da escritura autobiográfica, talvez mais presente nos textos em primeira pessoa, menos descentrados. Esse é um traço comum à literatura de Marguerite Duras, mesmo àquela declaradamente ficcional, sendo que em $\mathrm{La} V \mathrm{Vie}$ matérielle ela revela: "J'écris sur les femmes pour écrire sur moi, sur moi à travers les siècles" (DURAS, 1987,p. 53). Isso se aplica também para Lol V. Stein, Anne-Marie Stretter, Aurélia, ou Ágata.

Embora esses dois textos tenham personagens em comum com os primeiros - como por exemplo D. -, e o mesmo contexto histórico e social - o movimento de resistência francês -, Duras não é mais Duras, mas sim Thérèse. Mas mesmo em "La douleur", ou em "Monsieur X." não estamos certos de que aquela que narra é Duras. Mesmo porque a autora sempre se esforçou por colocar em dúvida o cumprimento do pacto autobiográfico em suas obras "não ficcionais", a começar por seu pseudônimo Duras, que consuma todo um trabalho de dissimulação. Segundo Vilain (2009, p. 62), ao escrever sobre L'Amant, "le je du passé renvoie à Marguerite Duras, qui renvoie ele-même à Marguerite Donnadieu, son véritable patronyme".

- Em primeiro lugar, vale dizer que essa instabilidade pode colocar em questão a veracidade em sentido estrito do conteúdo, mas pode manter-se fiel à autenticidade da escritura, conforme Philippe Lejeune:

Que dans sa relation à l'histoire (lointaine ou quasi contemporaine) du personnage, le narrateur se trompe, mente, oublie ou déforme - et

[23] Bajomée (1999, p. 169-173) fala da dimensão poética da obra de Duras, descrevendo o poético uma um deslocamento da linguagem ordinária, sendo que alguns escritos de Duras se organizam em torno de um ritmo quebrado, com a justaposição de frases, com uma organização textual singular, com a repetição de certas palavras, de certos temas, com a tradução de uma língua em outra. Neste artigo tratamos também de outros deslocamentos. 
erreur, mensonge, oubli ou déformation prendront simplement, si on les discerne, valeur d'aspects, parmi d'autres, d'une énonciation que, elle, reste authentique. Appelons authenticité ce rapport intérieur propre à l'emploi de la première personne dans le récit personnel; on ne confondra ni avec l'identité, que renvoie au nom propre, ni avec la ressemblance que suppose un jugement de similitude entre deux images différentes porte par un tierce personne. (LEJEUNE, 1975, p. 39-40)

Em segundo lugar, assim como em outras obras de caráter pretensamente "autobiográfico" 24 e confessional da autora, esses textos de La Douleur também têm a intenção de revelar, de alguma forma, sua identidade, bem como o real. No entanto, trata-se de uma outra forma de verdade, cujo critério não é a adequação mimética, mas o desvelamento do ser das coisas, um desvelamento que pode se operar por meio da ficção e da poesia. Nas palavras de Vilain (2009, p. 59): "à Duras d'introduire dans sa vie des éléments de fiction sans que ces éléments soient lus comme tels et perdent leur vraisemblance.". Nesse sentido, trata-se de uma verdade guiada pelo sensus communis, que aporta uma compreensão sobre sua identidade e sobre o mundo, não um conhecimento. Quando consideramos o desvelamento da verdade enquanto uma revelação do ser, não podemos esquecer que, de acordo com Heidegger, o traço essencial do ser é o velar iluminador ${ }^{25}$.

Vale mencionar que os textos narrados em terceira pessoa tratam de experiências limite, em situações limite, como a tortura de um colaboracionista por Thérèse, ou a experimentação do desejo sexual por um homem condenado, em um contexto no qual a purificação e cura do eu e do mundo se davam por meio da violência e da morte, e no qual o pensar e o julgar ainda não se faziam presentes, a justice d'épuration.

Nesse sentido, podemos supor que sejam textos que assumam a forma confessional, seja de fatos ocorridos e vivenciados pela autora, seja de acontecimentos que poderiam ter acontecido naquele contexto e que revelam possibilidades do real, e que portanto jogam uma luz sobre o sentido daquilo que foi experimentado pela autora naquele período, assim como pelos franceses envolvidos no mesmo contexto. Dessa forma, talvez a "confissão" do que seriam experiências limite, vivenciadas em 
alguma medida pela autora, medida esta que nos é impossível determinar, somente possa ser verdadeira se não houver um compromisso com o "dizer a verdade" em sentido estrito. Para ela, as experiências limite, como as que nos colocam na proximidade tanto do horror extremo quanto do desejo incontrolável, conteriam a verdade: “Jamais je n'avais raconté la mort de cette mouche, sa durée, sa lenteur, sa peur atroce, sa vérité" (DURAS, 1993, p. 51) (sem grifos no original).

O compromisso de Duras nessa "confissão" não é com memória que possui um estatuto irrefutável e atua como uma instância reconstrutiva da história, de uma tradição, que dota de legitimidade uma prática, sequer com um testemunho redentor ou reparador do eu, que repara o dano sofrido e recupera a unidade da identidade fragmentada pelo trauma, mas antes com uma recuperação poética de elementos que marcaram o passado e a memória da guerra e da resistência. Mesmo porque para Arendt, o juízo reflexivo, para que adquira uma dimensão geral, vai em busca de uma validade exemplar que não se restringe a objetos estéticos ou indivíduos que são paradigmas de certas virtudes, mas estende-se a eventos e personagens que carregam um significado que extrapola o mero acontecimento (LAFER, 2007, p. 299).

O sentido da guerra, como de muitos outros episódios que atravessaram a vida de Duras, e que ela compartilha com outros, está intimamente ligado à dor, como atesta o título da obra, e a compreensão desta, que apesar de não ser um fato objetivo, é fundamental para a apreensão do sentido do que foi a Shoah, a dominação alemã e o processo de libertação da França. Nesse sentido, o testemunho aqui talvez deva sua fidelidade a elementos que não são visíveis, mas que possuem o modo de ser do ocultamento. Tratando de uma de suas obras mais importantes, Le Vice Consul, a autora fala da dificuldade de escrever sobre aquilo que é fundamental às experiências, mas que não é visível: "Il n'y avait pas de plan possible pour dire l'amplitude du malheur parce qu'il n'y avait plus rien des événements visibles que l'auraient provoquée. Il n'y avait plus que la Faim et la Douleur" (grifos nossos) (DURAS, 1993, p. 40).

Assim, talvez a dor seja caracterizada aqui como uma marca na alma, sendo que aquilo que vale para o espírito não vale para a alma. $O$ discurso parece bastante adequado para a expressão de um pensamento lógico, no entanto, a vida da alma não aparece autenticamente dessa forma, se dá a ver apenas indiretamente, por sinais (ARENDT, 1992, p. 26). Maria Luiza Berwanger da Silva (2014) coloca que o desvelamento daquilo que não é aparente é um traço essencial da obra de Duras, "[c]onçue par ce projet de suggérer le fond à la surface [...]", considerando a "expérience 
durassienne du clair-obscur considéré par Maurice Blanchot comme lieu matriciel des incidentes imperceptibles".

E nesse aspecto a obra de Duras também é contemporânea conforme a concepção de Agamben, segundo a qual "seul peut se dire contemporain celui qui ne se laisse pas aveugler para les lumières du siècle et parvient à saisir en elles la part de l'ombre, leur sombre intimité" (AGAMBEN, 2009, p. 30). Mas como desvelar e trazer à aparência essas regiões sombrias?

Da mesma forma, a própria memória não é algo que se faz aparente e presente, estando repleta de regiões sombrias. A memória é marcada em diversas obras de Duras pelo signo do trauma e do esquecimento, que é chamada por Foucault de "mémoire sans souvenir" (vilAin, 2009, p. 63). O processo de escritura seria também um processo de decifração daquilo que já está lá, mesmo que não se tenha consciência dessa presença. Mas como decifrar e representar uma memória marcada por zonas de esquecimento significativas.

A poética de Duras opera justamente por meio da imaginação capaz de tornar presente aquilo que está ausente, visível o invisível. Assim, "écrire ce n'est pas raconter des histoires. C'est le contraire de raconter des histoires. C'est raconter tout à la fois. C'est raconter une histoire et l'absence de cette histoire que en passe par son absence." (DURAS, 1987, p. 31-2).

Uma das formas pela qual a escritora torna o imperceptível visível é conferindo uma aparência ao que de outra forma só apareceria inautenticamente. O corpo de Robert L., por exemplo, é o retrato da dor, a corporificação do sofrimento que por meio da linguagem adquire uma aparência que desafia a razão raciocinante. A percepção dos narradores e personagens que testemunham esse horror é aquela do olhar interno que traz o fundo à superfície, à aparência:

\footnotetext{
“de sorte que le réel ne soit plus à déchiffrer puisque, à l'instant d'être perçu comme tel, l'écriture l'a déjà modifié, transposé, passé au scanner du regard : le réel n'en est déjà plus un, ou il en est un autre que l'écriture exhume pour en faire son nouveau réel de référence, pour en extraire toute la charge affective, la vérité sensible, émotionnelle, vérité du moi peut-être plus essentielle.” (VILAIN, 2009, p. 68-9)
}

Os primeiros textos de La Douleur, em primeira pessoa, beiram o obsceno, o que revela que às vezes não conseguem superar inautenticidade da aparência daquilo cujo modo de ser é o do velamento. À superfície do corpo humano, de Robert L., do colaborador torturado, e da própria Marguerite narradora e personagem, que definha aos olhos de seu interlocutor, Monsieur X., é trazido o sofrimento da alma, a dor. Talvez, pretender 
desnudar e retratar o horror seja como olhar para os olhos da medusa, o que se aproxima do olhar para a face de Deus e representá-lo, sendo que aqueles que conseguem encarar o eidos voltam cegos ou loucos.

O eidos, assim, não poderia jamais ser atingido, sendo apenas um princípio formal, uma vez é da ordem do eterno e não do mundano. Os textos ficcionais da obra, "L’Ortie brisée" e "Aurelia Paris", conseguem expressar esses limites sendo que ao contrário dos primeiros optam pelo não dito, não mostrado:

Il retient enfermé en lui une chose qu'il ne sait pas dire, livrer. Cela parce qu'il ne la connait pas. Il ne sait pas comment on parle de la mort. Il est devant lui même comme le sont l'homme et l'enfant devant lui. L'homme et l'enfant savent. L'homme va parler à la place de l'étranger, mais de la même façon il se tairait. Tous ses forces sont faits pour éloigner le silence. Une chose est certaine. Si le silence n'était pas repoussé par les deus hommes, une phase dangereuse s'ouvrirait pour tous, les enfants, l'étranger, l'homme. Le mot qui vient en premier pour le dire est le mot de folie. (DURAS, 1985, p. 201)

Por outro lado, a representação literária serviria para uma aproximação da morte e do sofrimento do outro, incitando o reconhecimento. A dor seria experimentada e representada como uma espécie de comunidade entre aquele que sofre, aquele que percebe e o leitor. A obra pode ser vista com um lugar de encontro com o outro. Marguerite Duras procura, ao escrever, reduzir a distância que a separa do outro, seja este outro o amante chinês, seja ele o seu próprio marido que retorna do campo de concentração, Ter o miliciano, a "petite fille juive abandonnée", ou o jovem aviador inglês.

Consideramos por fim que a escritura de Duras esboça uma resposta à aporia existente nas visões de Benjamin sobre a experiência e o testemunho. Para Beatriz Sarlo, por um lado Benjamin reconhece as impossibilidades da experiência e de seu relato, mas por outro confere ao testemunho o mandato de um ato messiânico de redenção. Assim, se a própria narrativa constituir-se como vida e como uma forma de experiência, ela reabilitaria a possibilidade da experiência enquanto, e por meio do seu próprio relato. Assim, mesmo que Duras não tenha vivido aquilo que relata da forma como relata, ela o vive no momento da escritura, sendo que o texto adquire o caráter misto de representação e de apresentação.

A memória de Duras serviria como uma fonte da recriação, daí a afirmação de Vilain de que ela não escreve, mas reescreve. Ela reescreve as inscrições da memória e recria as zonas de esquecimento. Além disso, ela 
está sempre a reescrever aquilo que seria a sua experiência vivida, como em L'Amant, que sete anos mais tarde ganha uma nova versão com L'Amant de la Chine du Nord. No caso de La Douleur, o texto de mesmo título teria tido pelo menos três versões: aquela no diário, a de 1976 publicada na Revue Sorcières e a de 1985, quando da publicação do livro. E cada reescritura corresponderia a uma nova vivência daquilo que constituiu a primeira experiência, uma nova possibilidade de desenvolvimento da história, uma re-apresentação. Segundo PhilippeVilain (2009, p. 64-5) "il ne s'agit plus de rechercher le souvenir derrière soi comme dans l'autobiographie, mais également devant soi, dans l'écriture même, autant dans la rétrospection que dans la prospection qui accompagne la quête inventive de l'écriture."

\section{CONCLUSÃO}

La Douleur nos mostra como a literatura de testemunho pode partir da tentativa de compreensão daquilo que foi vivenciado como presente, da experiência vivida pelo eu, para a compreensão de eventos que incidiram sobre a autora.

Embora Marguerite Duras afirme que o ela mesma seja a única matéria de seus livros, ela também reclama uma escritura intransitiva e afirma que a história de sua vida não existe, apenas o romance de sua vida. Assim, sua própria identidade se afirma como aquela identidade cambiante e fragmentada de seus narradores e personagens. Sua própria verdade é aquela apresentada em seus livros, também a verdade do mundo, na medida em que o eu se insere nesse mundo, é por ele transformado e o transforma.

O critério do verdadeiro aqui não é o da mimese dos acontecimentos, mas o da recriação dessas experiências e memórias que revela o sentido dos acontecimentos. A imaginação e a ficção é que tornam possível essa constante reescritura da história e do real, o que refunda a relação entre a ficção e a verdade.

A ficcionalização e a expansão do vivido são constitutivas de seu próprio eu, e da própria realidade conforme vista através desse eu. Assim, essa característica de autoficção de sua narrativa testemunhal não falsifica sua identidade, nem a experiência vivida, mas explora as dependências ocultas do eu e do real, que não se revelam facilmente, ampliando-se para dentro e para fora, indo além do que é imediato e visível.

Essa ampliação consiste também em um deslocamento, que é mais natural a Duras do que a outros escritores, tendo em vista que ela sempre esteve deslocada. Deslocada de seu país, de sua nacionalidade, de sua 
língua, de sua família. A própria constituição de sua identidade partiu desse deslocamento e do contato com o outro, da tentativa de compreensão do que é estranho, do alheamento e retorno a si.

A solidão da atividade da escritura é aquela daquele que pensa e julga, uma solidão que nunca pode excluir a representação do outro em sua mente. Não podemos nos esquecer que a poética, para Arendt, descreve o caminho para o pensar. Embora ela afirme que a fluxo intermitente e infinito do pensar jamais possa ser capturado por qualquer representação, as metáforas e as representações têm o poder de designar elementos do pensamento que não são definidos pelo logos, mas sim pelo nous, e portanto seriam a princípio invisíveis, indefiníveis pela palavra (Platão, Carta VII). Mas a literatura de Duras faz com que esses sentidos das experiências emerjam da escuridão e adquiram uma perceptibilidade mínima. I 


\section{REFERÊNCIAS}

AGAMBEN, Giorgio. O que é o contemporâneo e outros ensaios. Chapecó: Argos, 2009.

ANTELME, Robert. L'espèce humaine. Paris: Gallimard, 1957.

ARENDT, Hannah. Entre o Passado e o Futuro. São Paulo: Editora Perspectiva, 2003.

ASSY, Bethânia. Eichmann, the Banality of Evil, and Thinking in Arendt's Thought. In: Seminar "Hannah Arendt's The Life of the Mind", spring. 1997, New School For Social Research, New York. Disponível em <https://www.bu.edu/ wcp/Papers/Cont/ContAssy.htm>. Acesso em 26 jan. 2015.

BAJOMÉE, Danielle. Duras ou la douleur. Paris: Duculot, 1999.

BENJAMIN, Walter. Charles Baudelaire um lírico no auge do capitalismo. São Paulo: Brasiliense, 1989.

BERWANGER DA SILVA, Maria Luiza. Marguerite Duras et l'expérience contemporaine. In: Colloque International Centenaire Marguerite Duras, 2014, São Paulo, Manuscrito.

DE MAN, Paul. Autobiography as De-facement. MLN, vol. 94, no 5, Comparative Literature, p. 919-930, 1979.

DURAS, Marguerite. La Douleur. Paris: P.O.L éditeur, 1985.

Écrire. Paris: Gallimard, 1993.

. La Vie matérielle. Paris: POL, 1987.

LAFER, Celso. Experiência, ação e narrativa: reflexões sobre um curso de Hannah Arendt. Estudos Avançados, vol. 21, no 60, pp. 289-304, ago. 2007.

LEJEUNE, Philippe. Le Pacte Autobiographique. Paris: Le Seuil, 1975.

NASCIMENTO, Evando. Derrida e a Literatura: "notas" de literatura e filosofia nos textos da desconstrução. 2 ed. Niterói: EdUFF, 2001. 
PERRONE-MOISÉS, Leyla. A criação do texto literário. In. Flores da escrivaninha. São Paulo: Companhia das Letras, 2006. p. 100-10.

SARLO, Beatriz. Tiempo passado: Cultura de la memoria y giro subjetivo. Una Discusión. Buenos Aires: Siglo XXI Editore, 2005.

SELIGMANN-SILVA, Márcio. (org.). História, memória, literatura: o Testemunho na Era das Catástrofes. Campinas: Editora da UNICAMP, 2003.

VILAIN, Philippe. L'autofiction en théorie. Paris: Les Éditions de la Transparence, 2009.

\section{BIBLIOGRAFIA CONSULTADA, MAS NÃO REFERENCIADA}

ARMEL, Aliette. Marguerite Duras et l'autobiographie. Le Castor Astral, 1990.

EAKIN, Paul John. What Are We Reading When We Read Autobiography? Narrative, Vol. 12, no 2, p. 121-131, 2004.

STRASSER, Anne. De l'autobiographie à l'autofiction: vers l'invention de soi. Autofiction(s). In: Colloque Cerisy, 2008. Presses universitaires de Lyon. 